\title{
Correspondence
}

\section{The role of holistic, patient-centred research}

I was struck by the article by Dr Crossley and its consideration of the tensions between being 'person centred yet scientific'. We strive to provide patient-centred care within the framework of evidence-based medicine, although we try to ascertain that evidence base using structured, standardised processes.

Other thinking behind the patient-centred approach has been developed by Fulford, expanding arguments surrounding the concept of disease. ${ }^{2}$ In his model of the 'balanced or fullfield model of health care' he examines the balance between the objective concept of disease and the subjective concept of illness. In these, he states, there is a tension between the views of the patient (who is subjectively experiencing the feelings and complaints of being ill) and the doctor (who takes the role of the expert in the area of disease, an objective, scientific concept).

If we want to emphasise the subjective experience of patients in our work, then I would like to suggest we increase our exposure to the subjective experience in research.

Categorising original research articles over two decades from the three highest-profile general psychiatric journals, rated by both journal impact factor and the proportion of psychiatrists reading them ${ }^{3}$ (the British Journal of Psychiatry, the American Journal of Psychiatry and Archives of General Psychiatry) showed that their focus is on objective research, with biological or epidemiological domains accounting for $70 \%$ of the articles published $(n=5710)$. When articles were rated using a narrow operational definition of whether their main aim was to study the subjective experience of the patient, ${ }^{4}$ only $2 \%$ (156 articles) met the criteria. Variables associated with subjective experience research (perhaps unsurprisingly) included psychosocial research topics (odds ratio $(O R)=10.2 ; 95 \% \mathrm{Cl}$ 7.4-14.2), and qualitative (OR $=34.6 ; 95 \% \mathrm{Cl} 5.74-208.7)$ and cross-sectional $(\mathrm{OR}=4.2 ; 95 \% \mathrm{Cl} 3.1-5.9)$ research methodologies. It is likely that journals from other disciplines (such as the social sciences and psychology) would have more articles pertaining to the subjective experience of patients, as would psychiatric journals with explicit aims to publish articles relating to ethics and patient-centred care; however, British psychiatrists are less exposed to these than to the journals investigated. $^{3}$

There is no reason why a subjective, values-based approach cannot sit alongside the objective, factual approach, and conflicts between values-based practice and evidencebased medicine are unnecessary. To be person-centred we must have a strong understanding of the factual evidence for our interventions, but also understand the patient's unique set of values and experiences. Evidence-based medicine promotes the integration of three key elements: best research evidence, clinical expertise and patient values. ${ }^{5}$ To do this effectively, patient-centred ethos should be applied when taking into account the illness experience, the person and the context in which the illness presents, to find common ground between both the physician's and the patient's perspective.

1 Crossley DR. Holistic psychiatry without the whole self. Psychiatrist 2012; 36: 97-100.
2 Fulford KWM. Concepts of disease and the meaning of patient-centred care. In Essential Practice in Patient-Centred Care (eds KWM Fulford, S Ersser, T Hope). Blackwell Science, 1996.

3 Jones T, Hanney S, Buxton M, Burns T. What British psychiatrists read. Questionnaire survey of journal usage among clinicians. Br J Psychiatry 2004; 185: 251-7.

4 Calton TC, D'Silva K, Cheetham A, Glazebrook C. Breaking the covenant: international schizophrenia research and the concept of patient centredness 1988-2004. In The History of the International Society for the Psychological Treatment of Schizophrenia and Other Psychoses (eds YO Alanen, AL Silver, de Chavez GM): 303-20. ISPS Publications, 2006.

5 Sackett DL, Strauss SE, Scott Richardson W, Rosenberg W, Haynes RB. Evidence-Based Medicine: How to Practice and Teach EBM (2nd edn). Churchill Livingstone, 2000.

Caroline S. Cooper, consultant psychiatrist, Pennine Care NHS Foundation Trust, UK, email: caroline.cooper1@nhs.net.

doi: $10.1192 / \mathrm{pb} .36 .6 .235$

\section{Holistic psychiatry}

David Crossley's paper on the self and holistic care ${ }^{1}$ is timely in the context of the heated debate over the place of spirituality and religion in clinical practice. In a commentary on this paper, one of us (C.C.H.C.) raised the difficult matter of challenging unhealthy spiritual/religious beliefs. ${ }^{2}$ In the course of making a point about the difficulties this entails, reference was made to a letter from a previously published correspondence between us, $^{3}$ suggesting that one possible response might be to argue that 'matters such as religion and spirituality should be excluded from all clinical practice'. This gave the unfortunate impression that the authors of that letter had taken this position. We would collectively like to correct this.

We are agreed that it would be impossible to completely exclude consideration of religion and spirituality from all aspects of clinical practice. Psychopathology often has religious content, and it can be important to understand the role of religion and spirituality in an individual patient's life. We are agreed that it is sometimes appropriate to involve chaplains and other religious advisors in helping people who have mental health problems. We are agreed that psychiatry cannot offer total solutions to mental illness and human unhappiness, and that in practice psychiatry is the application of a flawed science in the context of shared (but sometimes contended) professional values.

However, there are important differences between us as to best practice, and as to the proper approach to spirituality and religion when working with patients. Our fundamental disagreement concerns the extent to which it is appropriate or possible for psychiatrists to offer holistic care to patients, spirituality and religion being one important aspect of this.

C.C.H.C. believes that spirituality should routinely be considered as an important aspect of clinical practice, even where the patient does not directly raise it for discussion, and that a spiritual dimension to treatment renders it more meaningful and possibly more effective. He recognises that this creates real and complex challenges with regard to professional boundaries. However, he believes that the special 